\title{
Soğanlarda dip çürüklüğüne neden olan Fusarium oxysporum f. sp. cepae'nın büyüme ve gelişmesi üzerine bazı kalsiyum tuzlarının etkisi
}

\author{
İlayda ÜNSAL ${ }^{1}$, Sevgi KAȘ ${ }^{1}$, Muharrem TÜRKKAN ${ }^{1}$
}

1Ordu Üniversitesi Ziraat Fakültesi Bitki Koruma Bölümü, Ordu

*TÜBITTAK BİDEB 2209A (Proje No:1919B011700859)

Alınış tarihi: 1 Ekim 2018, Kabul tarihi: 20 Kasım 2018

Sorumlu yazar: Muharrem TÜRKKAN, e-posta: muharremturkkan@odu.edu.tr

\section{$\ddot{0} \mathbf{z}$}

Fusarium oxysporum f. sp. cepae'nın neden olduğu Fusarium dip çürümesi dünya çapında ekonomik öneme sahip en önemli hasat öncesi ve sonrası hastalıklardan biridir. Fusarium dip çürüklügünün kontrolünde dayanıklı soğan çeşitleri, ürün rotasyonu, solarizasyon, sanitasyon, biyolojik kontrol ve fungisit uygulamaları (tohum ve fide) önerilmektedir. Bununla birlikte, benomyl, carbendazim ve vinclozolin gibi bazı fungisitler hastalığın kontrolünde etkilidir, ancak yakın zamanda kanserojen etkileri nedeniyle yasaklanmıştır. Bu nedenle, hastalığın kontrolü için alternatif yöntemlere ihtiyaç duyulmaktadır. In vitro çalışmalar, kalsiyum propionatın \% 0.1 (\% 19.75) ve \% 0.25 (\% 41.44) kadar düşük konsantrasyonlarda F. oxysporum f. sp. cepae'nın misel gelişimini kalsiyum asetat, hidroksit, klorit, laktat, oksit ve sitrattan daha fazla azalttığını ve ayrıca ilk tuz ile ikinci grup tuzların etkilerinin arasındaki farkın istatistiksel olarak önemli olduğunu göstermiştir $(\mathrm{P}<0.05)$. Bununla birlikte, \% 1'lik kalsiyum hidroksit ve oksit konsantrasyonu fungus misel gelişimini tamamen engellerken, kalsiyum propionat \% 2'lik bir konsantrasyonda bile misel gelişimini \% 72.72'ye kadar azaltmıştır. Kalsiyum hidroksit ve oksit hariç, diğer beş tuzun spor çimlenmesi üzerinde olumsuz bir etkisi olmamıştır. Test edilen kalsiyum tuzları arasında, kalsiyum hidroksitin fungusa karşı en büyük toksisiteye sahip olduğu ve onu kalsiyum oksit ve kalsiyum propionatın takip ettiği bulunmuştur. In vivo çalışmalar, koruyucu uygulamada kalsiyum propionatın, patojen ile inokule edilmiş kontrole klyasla Fusarium dip çürümesinin şiddetini önemli ölçüde azalttığını göstermiştir $(\mathrm{P}<0.05)$. Bu çalışmadan elde edilen sonuçlar, kalsiyum propionatın, soğanlarda Fusarium dip çürüklüğünün kontrolünde kullanılabileceğini göstermektedir.

Anahtar kelimeler: Soğan, Fusarium dip çürüklüğü, kalsiyum tuzları, alternatif kontrol

Effect of some calcium salts on the growth and development of Fusarium oxysporum f. sp. cepae, the causal agent of Fusarium basal rot of onion

\begin{abstract}
Fusarium basal rot caused by Fusarium oxysporum $\mathrm{f}$. sp. cepae is one of the most important pre- and postharvest disease of economic significance worldwide. Resistant onion cultivars, crop rotation, solarization, sanitation, biological control and fungicide applications (seed and seedlings) are recommended in the controlling of Fusarium basal rot. However, a few fungicides such as benomyl, carbendazim and vinclozolin are effective in the control of the disease, but they have recently been banned due to their carcinogenic effect. Therefore, alternative methods are needed for the control of the disease. In vitro studies showed that calcium propionate at concentrations as low as $0.1 \%(19.75 \%)$ and $0.25 \%$ $(41.44 \%)$ reduced the mycelial growth of $F$. oxysporum f. sp. cepae more than calcium acetate, hydroxyde, chloride, lactate, oxide and citrate, and also the difference between the first salt and the effects of the second group of salts was statistically significant $\quad(\mathrm{P}<0.05)$. However, while $1 \%$
\end{abstract}


concentrations of calcium hydroxyde and oxide completely inhibited the mycelial growth of the fungus, calcium propionate was able to reduce the mycelial growth by up to $72.72 \%$ even at a concentration of $2 \%$. With the exception of calcium hydroxide and oxide, five other salts had no negative effect on spore germination. Of calcium salts tested, calcium hydroxyde was found to have the greatest toxicity against the fungus, followed by calcium oxide and calcium propionate. In vivo studies showed that calcium propionate in protective application signifcantly reduced the severity of Fusarium basal rot compared to pathogen-inoculated control $(\mathrm{P}<0.05)$. The results obtained from this study show that calcium propionate may be used in the control of Fusarium basal rot in onions.

Key words: Onion, Fusarium basal rot, calcium salts, alternative control

\section{Giriş}

Türkiye sebze tarımı için çok uygun bir ekolojiye sahip olup, yaklaşık 31 milyon ton sebze üretimi ile Çin, Hindistan ve Amerika Birleşik Devletleri'nden sonra 4. sırada yer almaktadır (FAO, 2016). Ülkemiz sebze üretiminde önemli bir yere sahip olan soğan (Allium cepae L.), toplam 66.431 ha alandan 2.270.506 ton ürün elde edilmektedir. Bu üretimin yaklaşılk \%77'si İç Anadolu (Ankara, Eskişehir), Akdeniz (Hatay, Adana), Karadeniz (Amasya, Çorum, Tokat) ve Marmara bölgeleri (Bursa)'nde gerçekleşmektedir (TUIK, 2016). Soğan ihracat açışından ülke ekonomisinde önemli bir yer tutmasına karşın, hasat öncesi ve sonrası çeşitli biyotik ve abiyotik faktörler üretim ve verimi olumsuz olarak etkilemektedir (Schwartz ve Mohan, 2008). Hasat sonrası çeşitli fungal (Aspergillus spp., Penicillium spp., Alternaria spp., Fusarium spp., Rhizopus spp., Colletotrichum spp. ve Botrytis spp.) ve bakteriyel (Pseudomonas spp., Lactobacillus spp. ve Erwinia spp.) hastalık etmenleri soğanlarda \% 35-40 civarında ürün kaybına neden olmaktadır (Kumar ve ark., 2015). Soğanlarda dip çürüklüğüne neden olan Fusarium oxysporum f. sp. cepae, dünyada soğan yetiştirilen Amerika Birleşik Devletleri, Brezilya, Güney Afrika, Hollanda, Hindistan, İngiltere, İran, İsveç, Japonya ve Uruguay gibi birçok ülkede rapor edilmiş olup, hem tarla hem de depo koşullarında önemli kayıplara neden olmaktadır (Everts ve ark., 1985; Cramer, 2000; Swift ve ark., 2002; Koike ve ark., 2007; Galván ve ark., 2008, Dissanayake ve ark., 2009; Southwood, 2010; Lager, 2011; Patil 2012;
Ghanbarzadeh ve ark., 2014). Soğan yetiștiriciliğinin yoğun olarak yapıldığı bazı ülkelerde hastalık tarlada \% 50 (Lacy ve Roberts, 1982) ve depoda ise \% 75 (Brayford, 1996; Stadnik ve Dhingra, 1996)'lere ulaşan kayıplara yol açabilmektedir. Ülkemizde de soğan yetiștiriciliği yapılan alanların dip çürüklüğü ile bulaşık olduğu ve soğan yumrularından da oldukça yüksek oranlarda izole edildiği bildirilmiştir (Özer ve Ömeroğlu, 1995; Özer ve ark., 2002; Türkkan ve Karaca, 2006). Hastalık etmeni tarlada soğanlarda solgunluk, dip ve kök çürüklüğünün yanı sıra soğan fidelerinin çıkışının gecikmesine ve çökertene neden olurken, hasat sonrası enfekteli soğan yumrularının kahverengileşmesine ve sulu bir hal alarak çürümesine yol açar (Langston ve Seebold, 2008). Soğan dip çürüklüğü hastalığı ile mücadelede dayanıklı çeşit kullanımı, ürün rotasyonu, solarizasyon, sanitasyon, biyolojik kontrol ve fungisit uygulamaları (tohum ve arpacık) önerilmektedir (Cramer, 2000). F. oxysporum f. sp. cepae'ya karşı dayanıklı soğan çeşitlerinin kullanılması ürün kaybını azaltabileceği, ancak etmenin virülensliği ve genetik yapısındaki değişiklerden dolayı dayanıklı çeşit yetiştiriciliğinin oldukça sinırladığı bildirilmektedir (Galván ve ark., 2008). Hastalığa karşı çeşitli fungisit (Benomyl, benomyl+mancozeb, carbendazim, carboxin, maneb, methoksimetil civa klorür, prochloraz, penncozeb, tebuconazole, thiram ve vinclozolin)'ler ile tohum ve arpacık uygulamalarının soğanlarda kök ve yumru çürüklügü zararını azalttığı rapor edilmiştir (Köycü ve Özer, 1997; Özer ve Köycü, 1998; Cramer, 2000; Sintayehu ve ark., 2011). Ancak günümüzde bu fungisitlerden bazıları insan ve çevre sağlığı üzerine olumsuz etkilerinden dolayı, dünyada ve ülkemizde yasaklanmıștır. Kaldı ki diğerleri de direkt olarak tüketilen ürünlerde kalıntı problemlerine yol açmaktadır. Bu yüzden bu hastalık etmeni ile savaşımda kimyasal savaşa alternatif olarak kullanılabilecek yeni kontrol yöntemlerinin araştırılmasına ihtiyaç duyulmaktadır. Bu amaca ulaşmak için kullanılabilecek en iyi yollarından biri, insan ve çevre sağllğı üzerine olumsuz bir etkisi olmayan/ya da sinırlı etkileri olan organik (benzoik, sitrik, sorbik, propinik asit vb.) ve inorganik (bikarbonat, karbonat vb.) bazı tuzların kullanımıdır. $\mathrm{Bu}$ bileşiklerin kullanımı Amerika Birleşik Devletleri'nde Gıda Kalite Koruma Yasası (Food Quality Protection Act, FQPA) ile düzenlenmiş olup, ABD Çevre Koruma Ajansı (Enviromental Protection Agency, EPA) tarafından genel olarak güvenli kabul 
edilen (Generally Recognized as Safe, GRAS) gida katkısı veya maddesi olarak tanımlanmaktadır (FDA, 2017). Geniş bir antimikrobiyal aktiviteye sahip olan bu bileşikler, sentetik fungisitlere klyasla oldukça düşük bir maliyete sahip olup, gıda sanayinde (koruyucu, pH düzenleyici, tat ve yapı düzenleyici madde) de katkı maddesi olarak yaygın bir şekilde kullanılmaktadır (Olivier ve ark., 1998; Davidson ve ark., 2005). Bu bileşiklerin antifungal etkinlikleri birçok fungal hastalık etmeni [Alternaria alternata, Botrytis cinerea, Penicillium expansum, P. italicum, $P$. digitatum, Phytophthora erythroseptica, P. infestans, P. nicotianea, Verticillium albo-atrum ve $V$. dahliae (Gabler ve Smilanick, 2001; Campanella ve ark., 2002; Palou ve ark., 2002; Droby ve ark. 2003; Mills ve ark., 2004; Türkkan ve ark., 2017)]'nde belirtildiği üzere, Fusarium sambucinum (Mecteau ve ark., 2002), F. solani var. coeruleum (Mecteau ve ark., 2008) ve Fusarium sulphureum (Li ve ark., 2009) gibi bazı hasat sonrası Fusarium türlerinin neden olduğu hastalıklarda da gösterilmiştir.

Bu çalışmada, soğan dip çürüklüğü etmeni $F$. oxysporum f. sp. cepae'ya karşı bazı kalsiyum tuzları (asetat, fosfat, hidroksit, klorit, laktat, oksit, propionat ve sitrat)'nın etkinlikleri hem in vitro hem de in vivo koşullarda araştırılmıştır.

\section{Materyal ve Yöntem}

\section{Fungal kültür}

Çalışmada kullanılacak F. oxysporum f. sp. cepae'ya ait izolat Ankara Üniversitesi, Ziraat Fakültesi, Bitki Koruma Bölümü'nden temin edilmiștir [(Ankara Üniversitesi Biyoteknoloji Projesi 2001-K-120-240-5 (2005-2007)]. İzolatın kültürleri Ordu Üniversitesi, Ziraat Fakültesi, Bitki Koruma Bölümü, Fitopatoloji Anabilim Dalı Mikoloji laboratuvarı fungal kültür koleksiyonunda muhafaza edilmektedir.

\section{Kalsiyum tuzları}

Çalışmada kullanılan organik ve inorganik kalsiyum tuzları Merck (Darmstadt, Germany) ve SigmaAldrich (Seelze, Germany) firmalarından satın alınmiştır.

\section{Kalsiyum tuzlarının misel gelişim üzerine etkileri}

Kalsiyum tuzlarının F. oxysporum f. sp. cepae'nın misel gelişimi üzerine etkisi Türkkan (2015)'ın metodu biraz değiştirilerek belirlenmiștir. Kalsiyum tuzlarının farklı konsantrasyonları $(\% 0.1,0.25,0.5$, 1.0 , ve $2.0, \mathrm{w} / \mathrm{v}$ ) otoklavda sterilize edilmiş ve yaklaşık $50{ }^{\circ} C^{\prime} y e$ soğutulmuş $100 \mathrm{ml}$ 'lik otoklav şişelerindeki patates dekstroz agar (PDA) besi ortamına eklenmiştir. Tuzlar manyetik karıștırıcı ile karıștırılarak homojen bir şekilde tüm besi ortamına karışması sağlanmıştır. Tuzların yukarıda belirtilen konsantrasyonlarını içeren PDA besi ortamı, $6 \mathrm{~cm}$ çapındaki plastik petri kutularına 8-10 ml olacak şekilde dökülmüștür. $\mathrm{Bu}$ petrilere, daha önceden PDA besi ortamında geliştirilmiş 7-10 günlük fungus kültürlerinden mantar delici ile alınan $4 \mathrm{~mm}$ çaplı misel disklerle inokule edilmiştir. Petriler streç film ile kaplandıktan sonra $25{ }^{\circ} \mathrm{C}$ 'de inkübe edilmiştir. Aynı koşullarda inkübe edilen kontrol grubu (sadece PDA besi ortamı içeren) petrilerdeki fungusların gelişmeleri günlük olarak izlenerek petriyi kaplamaya yakın olduğunda, kontrol ve kalsiyum tuzlarının farklı konsantrasyonlarını içeren petrilerdeki fungusların misel gelişimleri ölçülmüştür. Bu ölçümlerde fungusun en uzun ve kısa radyal gelișmeleri esas alınmıștır. Misel gelişmenin engellenmesi MGE (\%) = [(kpfg - tepfg) / $\mathrm{kpfg]} \times 100$ formülü kullanılarak hesaplanmıştır (Mecteau ve ark., 2002). Formüldeki MGE (\%), miselyal gelişmenin yüzde olarak engellemesini; kpfg, kontrol petrilerindeki fungal gelişmeyi; tepfg, tuz eklenmiş petrilerdeki fungal gelişmeyi ifade etmektedir. Deneme her tuz konsantrasyonu için 6 tekerrürlü olacak şekilde yürütülmüștür.

\section{Kalsiyum tuzlarının konidi çimlenmesi üzerine etkileri}

F. oxysporum f. sp. cepae izolatı PDA besiyerinde 25 ${ }^{\circ}$ C'de 7-10 gün geliştirilmiş ve bu kültürün üzerine steril distile su eklenerek spatülle kazınmış ve sporların suya geçmeleri sağlanmıştır. $\mathrm{Bu}$ spor süspansiyonu iki kat steril filtre kağıdından geçirilerek miselyum kalıntıları süspansiyondan uzaklaştırılmıştır. Hazırlanan bu süspansiyondaki sporlar, Thoma lamında (hemocytometre) saylarak konsantrasyonları $5 \times 10^{5}$ konidi $\mathrm{mL}^{-1}$ ye ayarlanmıştır (Mecteau ve ark., 2002). Tuzlarının farklı konsantrasyonları (\% 0.1, 0.25, 0.5, 1.0, ve 2.0, $\mathrm{w} / \mathrm{v}$ ) otoklav edilmiş PDA besi ortamına eklenmiştir. Tuzlar manyetik karıștırıcı ile karıștırılarak homojen bir șekilde tüm besi ortamına karıșması sağlanmıș ve tuz içeren PDA besi ortamı, $6 \mathrm{~cm}$ çapındaki plastik petri kaplarına $10 \mathrm{ml}$ olacak şekilde dökülmüştür. Hazırlanan spor süspansiyonu tuz eklenmiş ve eklenmemiş (kontrol) PDA besi ortamı içeren her Petri kabına 30-50 $\mu \mathrm{L}$ olacak șekilde yayılmıștır. Kültürler 24 saat boyunca $24 \pm 1{ }^{\circ} \mathrm{C}$ 'de inkübasyona bırakılmış ve spor büyüklüğünün en az yarısı kadar çim tüpü oluşturmuş sporlar çimlenmiş olarak kabul edilmiştir. 


\section{Kalsiyum tuzlarının toksisitelerinin belirlenmesi}

Fungusun misel gelişmesini \% 50 oranında azaltan konsantrasyon $\left(\mathrm{EC}_{50}=\right.$ etkili doz) IBM SPSS Statistic 20 paket programı kullanılarak probit analizi ile hesaplanmıştır. Miselyal gelişmeyi tamamen engelleyen en küçük konsantrasyon (MIC= minimum inhibition concentration) paralel denemelerle belirlenmiștir (Türkkan, 2015).

Ayrıca tuzların fungusidal veya fungistatik etkileri Thompson (1989) ve Tripathi ve ark. (2004)'nin metodları izlenerek belirlenmiştir. Buna göre gelişmeyen fungus diskleri petrilerden alınarak, taze PDA besi ortamı içeren petrilere tekrar aşılanmıştır. Fungusun gelişmeleri $25{ }^{\circ} \mathrm{C}$ 'de 9 gün boyunca izlenmiştir. $\mathrm{Bu}$ süre zarfında fungusta geri dönüşümsüz olarak hiç bir gelişme gözlenmemişse, bu konsantrasyon fungusu tamamen engelleyen konsantrasyon $\quad(M F C=$ minimum fungicidal concentration) olarak belirlenmiştir.

\section{Kalsiyum tuzlarının tedavi edici ve koruyucu} etkilerinin belirlenmesi

$\mathrm{Bu}$ amaç için alınan soğan yumruları kullanılıncaya kadar karanlıkta $4{ }^{\circ} C^{\prime}$ de tutulmuştur. Soğan yumrularının dip kısımları maket bıçağı ile kesilip uzaklaştırıldıktan sonra $15 \mathrm{dk}$ süre ile \% $0.5^{\prime}$ lik sodyum hipoklorit tutulmuştur. Daha sonra üç kez steril saf su serisinden geçirildikten sonra steril kabin içerisinde kurutulmuştur. Soğan yumrularının dip kısımlarında bir mantar delici yardımı ile $4 \mathrm{~mm}$ çapında bir delik açılmıştır.

Tuzların tedavi edici ve koruyu etkileri Mecteau ve ark. (2002)'nin metodu biraz değiştirilerek belirlenmiştir. Tuzların tedavi edici etkilerinin belirlenmesi için "Kalsiyum tuzlarının konidi çimlenmesi üzerine etkileri” başlığı altında belirtilen fungus spor süspansiyonundan $30-35 \mu \mathrm{l}$ yumrulardaki yara yerlerine inokule edilmiştir. Yumrular $25{ }^{\circ} \mathrm{C}^{\prime}$ de 1 gün süreyle karanlıkta tutulmuştur. Daha sonra yumrular $10 \mathrm{dk}$. süreyle tuzların \% 2 konsantrasyonlarına, kontrol yumruları ise steril safsuya daldırılmıștır. Plastik kaplara alınan yumrular $25^{\circ}{ }^{\circ}$ 'de 7 gün süreyle karanlıkta inkübe edilmiștir.

Tuzların koruyucu etkilerinin belirlenmesinde ise yumrular önce farklı tuz konsantrasyonlarına daldırılıp $10 \mathrm{dk}$ tutulduktan sonra, 3 saat süreyle steril kabin içerisinde kurutulmuştur. Daha sonra yukarıda belirtilen miktarlarda spor süspansiyonu ile yumrular inokule edilmiş ve inkübasyona bırakılmıștır. Tedavi edici ve koruyu uygulamaların inkübasyon periyodundan sonra hastalık şiddeti yumru üzerindeki lezyon alanı üzerine konulan şeffaf bir asetat kağıt kullanılarak çıkarılmıştır. Daha sonra bir tarayıcı yardımıyla taranıp 24-bit bmp dosyaları olarak kaydedilmiştir. Lezyon alanları $\left(\mathrm{cm}^{2}\right)$ Digimizer programı kullanılarak (Digimizer Version 4.0.0.0 for Windows 2005-2011 MedCalc Software bvba Broekstraat 52, 9030 Mariakerke, Belgium) hesaplanmıştır. Deneme 4 tekerrürlü olacak şekilde yürütülmüştür (Türkkan, 2015).

\section{İstatistik analiz}

Tüm istatistiksel analizler SPSS (version 19, Property of SPSS, Inc.;IBM Company) programı kullanılarak yapılmıștır. Elde edilen veriler ayrı ayrı tek yönlü varyans analizine tabi tutularak ortalamalar arasındaki önemli farklılıklar TukeyHSD $(\mathrm{P}<0.05)$ testi ile belirlenmiştir.

\section{Bulgular ve Tartışma}

\section{Kalsiyum tuzlarının misel gelişimi ve konidi çimlenmesi üzerine etkileri}

Çalışmada kullanılan kalsiyum tuzları (asetat, hidroksit, klorit, laktat, oksit, propionat ve sitrat)'nın F. oxysporum f. sp. cepae'nın misel gelişimi üzerine etkileri birbirinden farklılık göstermiştir (Çizelge 1). Kalsiyum propionat \% 0.1 ve 0.25 konsantrasyonlarda diğer tüm tuzlardan fungus misel gelişimini azaltmada önemli derecede farklı bulunmuştur $(\mathrm{P}<0.05)$. Ancak kalsiyum hidroksit ve oksitin artan konsantrasyonları ile birlikte misel gelişimini azaltmada kalsiyum propionattan daha etkili olduğu gözlenmiştir. Dahası kalsiyum hidroksit ve oksit $\% 1$ konsantrasyonlarında misel gelişimini tamamen engellemiştir ve tam engellemenin gerçekleştiği konsantrasyonlar diğer tüm konsantrasyonlardan istatistiksel olarak önemli ölçüde farklı bulunmuştur $(\mathrm{P}<0.05)$. Mevcut çalışmanın sonuçlarına benzer olarak Bigss ve ark. (1997) kalsiyum propionatın $600 \mathrm{mg} / \mathrm{l}$ (\% 0.06 , w/v)'lik bir konsantrasyonda şeftali kahverengi çürüklük etmeni Monilinia fructicola'nın misel gelişimini kalsiyum hidroksit ve oksitten çok daha kuvvetli bir şekilde engellediğini tespit etmişlerdir. Başka bir çalışmada elma ve armut depo çürüklüğü Botrytis cinerea'nın misel gelişimini tamamen engellemek için kalsiyum propionatın \% 5 (w/v)'lik konsantrasyonunun yeterli olduğunu, ancak Penicillium expansum için daha yüksek konsantrasyonlara ihtiyaç duyulduğu gösterilmiştir (Droby ve ark., 2003). Mills ve ark. (2004) 0.2 M (\% 3.7) konsantrasyonda kalsiyum propionatın Alternaria alternata, B. cinerea, Fusarium solani var. 
coeruleum, Phytophthora erythroseptica, P. infestans, Verticillium albo-atrum ve $V$. dahliae gibi çeşitli patates patojenlerinin misel gelişimini \% 38-79 oranında azalttı̆̆ını belirlemişlerdir. Campanella ve ark. (2002) kalsiyum oksit ve propionatın farklı konsantrasyonları $(300,600$ ve 1200 ppm)'nın turunçgil Phytotphthora kök çürüklüğü etmeni Phytophthora nicotianae'nın misel gelişimini kontrole kıyasla önemli oranda azalttığını, fakat kalsiyum asetat, laktat ve kloritin kontrolden farklı olmadığını rapor etmişlerdir. Mevcut çalışmada \% 2'lik konsantrasyonlarında kalsiyum asetat ve sitrat kontrole kıyasla misel gelişimini nispeten azaltmış, kalsiyum laktat kontrolden farksız bulunmuş, fakat kalsiyum klorit kontrole kıyasla misel gelişimini artırmıştır $(\mathrm{P}<0.05)$. Armut depo çürüklük etmenleri $A$. alternata ve $P$. expansum'un misel gelişimlerinin $\%$ 2'lik kalsiyum klorit konsantrasyonundan etkilenmediği, ancak \% 6’lık bir konsantrasyonda her iki fungusun misel gelişmelerini sırasıyla \% 22.1 ve \% 25.0 oranında azalttığı kaydedilmiştir (Tian ve ark., 2001; Maouni ve ark., 2007). Mecteau ve ark. (2002) kalsiyum kloritin 0.2 M ( $\%$ 2.9 $)^{\prime}$ lık bir konsantrasyonda patates kuru çürüklük etmeni Fusarium sambucinum'un misel gelişimini \% 4.6 oranında engelleyebildiğini rapor etmişlerdir. Aynı tuzun düşük konsantrasyon (1000 mg/lt)'da elmalarda beyaz çürüklük etmeni Botryosphaeria dothidea'nın misel gelişimini artırdığ belirlenmiștir (Biggs, 2004).

Kalsiyum asetat, klorit, laktat, propionat ve sitratın çalışmada kullanılan en yüksek konsantrasyonda bile F. oxysporum f. sp. cepae'nın konidi çimlenmesini etkilemediği gözlenmiştir. Çalışmamızın sonuçlarına benzer olarak kalsiyum kloritin farklı konsantrasyon $(0.125,0.25,0.5,1.0,2.0 \text { ve } 3.0 \%, w / v)^{\prime} l a r ı n ı n$ üzümlerde kurşuni küf etmeni $B$. cinerea'nın konidi çimlenmesini etkilemediği belirlenmiştir (Youssef ve
Roberto, 2014). Başka bir çalışmada kalsiyum klorit, hidroksit ve propionatın $B$. dothidea'nın farklı izolatları (PA-1 ve PA-2)'nın konidi çimlenmelerini kontrole kıyasla artırdığı ve istatistiksel olarak bunların birbirinden farksız olduğu tespit edilmiștir $(\mathrm{P}=0.05)$ (Biggs, 2004). Halbuki mevcut çalışmada kalsiyum hidroksit ve oksitin \% 0.1 ve 0.25 'lik konsantrasyonları F. oxysporum f. sp. cepae'nın konidi çimlenmesini sırasıyla \% 94.33 - \% 88.67 ve \% 95.67 - \% 95.50 oranında engellemiş ve tam engelleme \% 0.5 kalsiyum hidroksit ve \% 1 kalsiyum oksit konsantrasyonlarında gerçekleşmiştir. Ayrıca bu iki tuzun \% 0.1'lik konsantrasyonları hariç, diğer tüm konsantrasyonları konidi çimlenmesini engelleme bakımından birbirinden istatistiksel olarak farksız bulunmuştur $(\mathrm{P}<0.05)$.

\section{Kalsiyum tuzlarının toksisiteleri}

F. oxysporum f. sp. cepae'nın misel gelişimi üzerine toksik etkileri bakımından kalsiyum hidroksit ilk sırada yer almış ve onu sırasıyla oksit ve propionat takip etmiştir (Çizelge 2). Kalsiyum asetat ve sitratın $\mathrm{EC}_{50}$ değerleri \% 2'den büyük bulunmuştur. Ancak kalsiyum klorit ve laktatın misel gelişimi üzerine herhangi bir engelleyici etkisi olmadığından dolayı bu iki tuzun $\mathrm{EC}_{50}$ değerleri hesaplanamamıştır. Çalışmamızın sonuçlarına benzer olarak Youssef ve Roberto (2014) B. cinerea'nın misel gelişimine olumsuz bir etkisi olmayan kalsiyum klorit için $\mathrm{EC}_{50}$ değeri tespit edemediklerini ve MIC değerinin de \% 3 (çalışmada kullanılan en yüksek konsantrasyon)'ten büyük olduğunu rapor etmişlerdir. Mevcut çalışmada da kalsiyum hidroksit ve kalsiyum oksit hariç, geri kalan tüm tuzların MIC ve MFC değerlerinin \% 2'den büyük olduğu tespit edilmiştir. $\mathrm{Bu}$ iki tuzun fungistatik etkilerinin gerçekleștiği \% 1 konsantrasyon değeri, aynı zamanda fungisidal konsantrasyon değeri olarak belirlenmiştir.

Çizelge 1. Fusarium oxysporum f. sp. cepae'nın misel gelişimi üzerine kalsiyum tuzlarının engelleyici etkileri

\begin{tabular}{|c|c|c|c|c|c|c|c|}
\hline \multirow{2}{*}{$\begin{array}{c}\text { Konsantrasyon } \\
(\%, w / v)\end{array}$} & \multicolumn{7}{|c|}{ Kalsiyum tuzları } \\
\hline & Asetat & Hidroksit & Klorit & Laktat & Oksit & Propionat & Sitrat \\
\hline 0.10 & $7.43 \mathrm{bc}^{\mathrm{a}, \mathrm{b}}, \mathrm{B}^{\mathrm{c}}$ & $-0.04 \mathrm{~d}, \mathrm{BCD}$ & $-4.63 a b, D$ & $4.45 \mathrm{a}, \mathrm{BC}$ & $4.27 \mathrm{~cd}, \mathrm{BC}$ & $19.75 \mathrm{e}, \mathrm{A}$ & $-2.17 \mathrm{~b}, \mathrm{CD}$ \\
\hline 0.25 & $14.86 \mathrm{ab}, \mathrm{B}$ & 20.12 c, B & $-3.45 a b, D$ & $1.85 \mathrm{ab}, \mathrm{CD}$ & $11.65 \mathrm{c}, \mathrm{BC}$ & $41.44 \mathrm{~d}, \mathrm{~A}$ & $-6.35 b, D$ \\
\hline 0.50 & $14.91 \mathrm{ab}, \mathrm{C}$ & $76.53 \mathrm{~b}, \mathrm{~A}$ & $-6.07 a b, D$ & $-1.39 \mathrm{ab}, \mathrm{CD}$ & $35.73 \mathrm{~b}, \mathrm{~B}$ & 48.67 c, B & $-3.34 b, D$ \\
\hline 1.00 & $16.99 \mathrm{ab}, \mathrm{C}$ & $100.00 \mathrm{a}, \mathrm{A}$ & $-8.19 b, E$ & $-2.82 \mathrm{~b}, \mathrm{DE}$ & $100.00 \mathrm{a}, \mathrm{A}$ & $59.91 \mathrm{~b}, \mathrm{~B}$ & $2.07 \mathrm{~b}, \mathrm{D}$ \\
\hline 2.00 & $22.22 \mathrm{a}, \mathrm{C}$ & $100.00 \mathrm{a}, \mathrm{A}$ & $-9.82 \mathrm{~b}, \mathrm{~F}$ & $-1.66 \mathrm{ab}, \mathrm{E}$ & $100.00 \mathrm{a}, \mathrm{A}$ & $72.72 \mathrm{a}, \mathrm{B}$ & $11.14 \mathrm{a}, \mathrm{D}$ \\
\hline 0.00 & $0.00 \mathrm{c}, \mathrm{A}$ & $0.00 \mathrm{~d}, \mathrm{~A}$ & $0.00 \mathrm{a}, \mathrm{A}$ & $0.00 \mathrm{ab}, \mathrm{A}$ & $0.00 \mathrm{~d}, \mathrm{~A}$ & $0.00 \mathrm{f}, \mathrm{A}$ & $0.00 \mathrm{~b}, \mathrm{~A}$ \\
\hline
\end{tabular}

aAynı harfle başlayan ortalamalar arasındaki farklılık Tukey-HSD $(\mathrm{P}<0.05)$ testine göre istatistiksel olarak önemsizdir.

bAynı tuzların konsantrasyonları arasındaki farklılığı göstermektedir.

cFarklı tuzların konsantrasyonları arasındaki farklılı̆̆ göstermektedir. 
Çizelge 2. Fusarium oxysporum f. sp. cepae'nın misel gelişimi üzerine kalsiyum tuzları (\%, w/v)'nın toksik etkileri

\begin{tabular}{lccc}
\hline Kalsiyum tuzları & ${ }^{\mathrm{aED}} \mathrm{E}_{50}$ & ${ }^{\mathrm{b}} \mathrm{MIC}$ & ${ }^{\mathrm{c}} \mathrm{MFC}$ \\
\hline Asetat & $>2$ & $>2$ & $>2$ \\
Hidroksit & 0.35 & 1 & 1 \\
Klorit & $\mathrm{B}^{\mathrm{d}}$ & $>2$ & $>2$ \\
Laktat & $\mathrm{B}$ & $>2$ & $>2$ \\
Oksit & 0.47 & 1 & 1 \\
Propionat & 0.53 & $>2$ & $>2$ \\
Sitrat & $>2$ & $>2$ & $>2$ \\
\hline
\end{tabular}

aMisel gelișimini 50\% oranında azaltan konsantrasyon.

bMinimum engelleyici konsantrasyon.

cMinimum fungisidal konsantrasyon.

dBelirlenemedi.

Mills (2004), alüminyum klorit, sodyum klorit, sodyum süksinat, kalsiyum hidroksit ve kalsiyum oksitin $0.2 \mathrm{M}$ konsantrasyonlarının patates pembe çürüklüğü etmeni (Phytophthora erythroseptica) için fungitoksik veya fungisitatik olduğunu rapor etmiştir.

\section{Soğan dip çürüklüğüne karşı kalsiyum tuzlarının koruyucu ve tedavi edici etkileri}

Soğan dip çürüklüğüne karșı kalsiyum tuzlarının \% 2 konsantrasyonlarının koruyucu ve tedavi edici etkileri değerlendirildiğinde, kalsiyum asetat, hidroksit, klorit, laktat, oksit ve sitrat her iki uygulamada da inokule edilmiş kontrolden farklı bulunmamıştır $(\mathrm{P}<0.05)$ (Şekil 1). Ancak kalsiyum propionatın koruyucu uygulaması soğan dip çürüklüğü hastalığını hemen tamamen engellediği ve hastalık etmeni ile inokule edilmiş pozitif kontrol ile kıyaslandığında istatistiksel olarak oldukça önemli farklılık olduğu bulunmuştur $(\mathrm{P}<0.05)$.

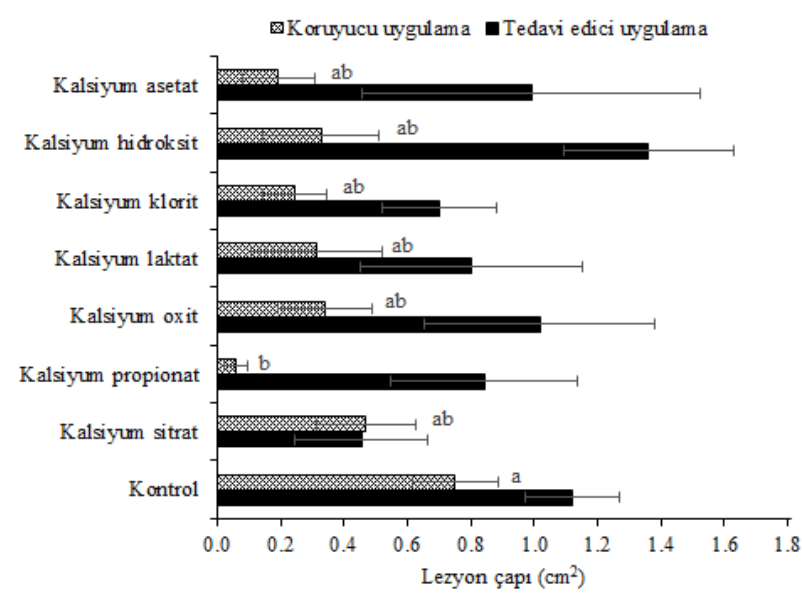

Şekil 1. Soğan dip çürüklüğüne karşı \% 2 konsantrasyonda kalsiyum tuzlarının koruyucu ve tedavi edici etkileri (Aynı harfle başlayan ortalamalar arasındaki farklılık TukeyHSD $(\mathrm{P}<0.05)$ testine göre istatistiksel olarak önemsizdir).
Havuçlarda siyah kök çürüklügü hastalığı [Chalara elegans (Thielaviopsis basicola)]'a karşı farklı organik ve inorganik tuzların kullanıldığı bir çalışmada kalsiyum propinat $(0.1 \mathrm{M}=\%$ 1.86)'ın standart uygulama olan sodyum hipoklorit $(100 \mu \mathrm{g} / \mathrm{ml}$ klorin $)$ ve diğer tuz (amonyum bikarbonat, potasyum karbonat, potasyum sorbat ve sodyum bikarbonat) uygulamalarından daha etkili bir şekilde hastalık gelişimini azalttı̆̆ belirlenmiştir (Punja ve Gaye, 1993). Mills ve ark. (2005) patates pembe çürüklüğü (P. erythroseptica)'ne karşı çeşitli bileşikler ve kalsiyum propionat $(0.2 \mathrm{M})$ '1 hem tedavi edici hem de koruyucu uygulama olarak değerlendirdiği bir çalışmada, kalsiyum propionatın sadece koruyucu olarak uygulandığında hastalık şiddetini kontrole kıyasla önemli oranda azalttığını belirlemișlerdir. Ayrıca kalsiyum kloritin \% 4 ve 6 gibi yüksek konsantrasyonlarının armut depo çürüklük etmenleri $A$. alternata ve $P$. expansum'a karşı etkili olduğu bildirilmiştir (Maouni ve ark., 2007). Mevcut çalışmada soğan dip çürüklüğü etmeni $F$. oxysporum f. sp. cepae'ya karşı in vitro olarak koşullarda etkili bulunan tuzların in vivo da etkili olmadığı gözlenmiş olup, bu durum daha öncede patates gümüş kabukluluk (Helminthosporium solani), fasulye pası (Uromyces appendiculatus) ve buğday pası (Puccinia triticina) gibi bazı patojenlerin kontrolünde de rapor edilmiștir (Hervieux ve ark., 2002; Arslan ve ark., 2006). Bu uyumsuzluklarda konukçu doku-tuz interaksiyonları ve bazı çevresel faktörlerin etkili olduğu belirtilmektedir (Punja ve Grogan, 1982; Hervieux ve ark., 2002). Bu çalışmada in vitro denemelerde kalsiyum propionat, kalsiyum hidroksit ve kalsiyum oksitin gerisinde kalmasına rağmen, in vivo koruyucu uygulamalarda diğer 6 kalsiyum tuzundan daha etkili bulunmuştur.

\section{Teşekkür}

Bu çalışma Tübitak BİDEB 2209A (Proje No:1919B011700859) tarafından desteklenmiştir.

\section{Kaynaklar}

Arslan, U., Ilhan, K., Karabulut, O. A. 2006. Evaluation of food additives and low-toxicity compounds for the control of bean rust and wheat leaf rust. Journal Phytopathol, 154:534-541.

Biggs, A. R. 2004. Effect of inoculum concentration and calcium salts on infection of apple fruit by Botryosphaeria dothidea. Plant Disease, 88(2):147151.

Brayford, D. 1996. Fusarium oxysporum f. sp. cepae. Mycopathologia,

133:

39-40. 
Campanella, V., Ippolito, A., Nigro, F. 2002 Activity of calcium salts in controlling Phytophthora root rot of citrus. Crop Protection, 21:751-756.

Cramer, C. S. 2000. Breeding and genetics of Fusarium basal rot resistance in onion. Euphytica, 115:159166.

Davidson PM, Sofos JN, Branen AL. (2005) Antimicrobials in Food, 3rd edn. Boca Raton, FL, USA, CRC Press, pp 721.

Dissanayake, M.L.M.C., Kashima, R., Tanaka, S., Ito, S-I., 2009. Genetic diversity and pathogenicity of Fusarium oxysporum isolated from wilted Welsh onion in Japan. Journal of General Plant Pathology, 75: 125-130.

Droby, S., Wisniewski, M. E., El Ghaouth, A., Wilson, C. 2003. Influence of food additives on the control of postharvest rots of apple and peach and efficacy of the yeast-based biocontrol product Aspire. Postharvest Biology and Technology, 27:127-135.

Everts, K.L., Schwartz, H.F., Epsky, N.D., Capinera, J.L., 1985. Effects of maggots and wounding on occurrence of Fusarium basal rot of onions in Colorado. Plant Disease 69: 878-882.

FAO, 2016. http://www.fao.org/faostat/en/\#data/QC (Erişim tarihi: 20.09.2018)

FDA, 2017. https://www.fda.gov/food/ingredientspack aginglabeling/gras/default.htm

Gabler, F.M., Smilanick, J.L., 2001. Postharvest control of table grape gray mold on detached berries with carbonate and bicarbonate salts and disinfectants. Am. J. Enol. Viticult. 52: 12-20.

Galván, G. A., Koning-Boucoiran, C. F. S., Koopman, W. J. M., Burger-Meijer, K., González, P. H., Waalwijk, C., Kik, C., Scholten, O. E. 2008. Genetic variation among Fusarium isolates from onion, and resistance to Fusarium basal rot in related Allium species. European Journal of Plant Pathology, 121: 499-512.

Ghanbarzadeh, B., Goltapeh, E.M., Safaie, N., 2014. Identification of Fusarium species causing basal rot of onion in East Azarbaijan province, Iran and evaluation of their virulence on onion bulbs and seedlings. Archives of Phytopathology and Plant Protection, 47(9): 1050-1062.

Hervieux, V., Yaganza, E. S., Arul, J., Tweddell, R. J. 2002. Effect of organic and inorganic salts on the development of Helminthosporium solani, the causal agent of potato silver scurf. Plant Disease, 86:1014-1018.

Koike, S.T., Gladders, P. and Paulus, A.O., 2007. Vegetable Diseases: A Colour Handbook. Manson Publishing, London, UK.
Köycü, N. D., Özer, N. 1997. Determination of seedborne fungi in onion and their transmission to onion seeds. Phytoparasitica, 25: 25-31.

Kumar, V., Sunil Sharma, N., Sagar, N. A., 2015. Post Harvest Management of Fungal Diseases in Onion. Int. J. Curr. Microbiol. App. Sci, 4(6): 737-752.

Lacy, M.L., Roberts, D.L. 1982. Yields of onion cultivars in Midwestern organic soils infested with Fusarium oxysporum f.sp. cepae and Pyrenochaeta terrestris. Plant Disease, 66: 1003-1006.

Lager, S., 2011. Survey of Fusarium species on yellow onion (Allium cepa) on Öland. Swedish University of Agricultural Science, MSc dissertation, Uppsala, Swedish, 34p.

Langston, D.B., Seebold, K.W., 2008. Fusarium basal rot. In: Schwartz HF, Mohan SK. (2nd eds) Compendium of Onion and Garlic Diseases. St Paul, MN, USA, APS Press, pp 12-14.

Li, Y. C., Bi, Y., Ge, Y. H., Sun, X. J., Wang, Y. 2009. Antifungal activity of sodium silicate on Fusarium sulphureum and its effect on dry rot of potato tubers. Journal Food Science, 74:213-218.

Maouni, A., Lamarti, A., Aidoun, A., Khaddor, M., Badoc, A. 2007. Effect of benzimidazole fungicides and calcium chloride on Alternaria alternata and Penicillium expansum rot during storage of pears. Afric. J. Biotec., 6 (11): 1289-1292.

Mecteau, M. R., Arul, J., Tweddell, R. J. 2002. Effect of organic and inorganic salts on the growth and development of Fusarium sambucinum, a causal agent of potato dry rot. Mycological Research, 106:688-696.

Mecteau, M., Arul, J., Tweddell, R., 2008. Effect of different salts on the development of Fusarium solani var. coeruleum, a causal agent of potato dry rot. Phytoprotection, 89(1): 1-6.

Mills, A. A. S. 2004. Salt Compounds as Control Measures Against Post-Harvest Tuber Diseases of Potato. Department of Biology, Faculty of Science, University of Prince Edward Island, M. Sc. Thesis, Charlottetown, Canada, 123p.

Mills, A. A. S., Platt, H. W., Hurta, R. A. R. 2004. Effect of Salt Compounds on Mycelial Growth, Sporulation and Spore Germination of Various Potato Pathogens. Postharvest Biology and Technology, 34:341-350.

Mills, A. A. S., Platt, H. W., Hurta, R. A. R. 2005. Salt compounds as control agents of late blight and pink rot of potatoes in storage. Can. Journal Plant Pathoogy, 27:204-209.

Olivier, C., Halseth, D. E., Mizubuti, E. S. G., Loria, R., 1998. Postharvest application of organic and inorganic 
salts for suppression of silver scurf on potato tubers. Plant Disease, 82: 213-217.

Özer, N., Köycü, N. D. 1998. Evaluation of seed treatments for controlling Aspergillus niger and Fusarium oxysporum on onion seed. Phytopathologia Mediterranea, 37: 33-40.

Özer, N., Ömeroğlu, M. 1995. Chemical control and determination of fungal causal agents of wilt disease of onion in Tekirdag Province. J. Turk. Phytopath., 24(2): 47-55.

Özer, N., Köycü, N.D., Mirik, M., Soran, H., Boyraz, D., 2002. Effect of some organic amendments on onion bulb rot. Phytoparasitica, 30: 429-433.

Patil, A.M., 2012. Studies on onion basal rot caused by Fusarium oxysporum Schlecht Fr f. sp. cepae (Hans.) Snyd. and Hans. University of Agricultural Sciences, MSc dissertation, Dharwad, India, 64p.

Palou, L., Usall, J., Smilanick, J.L., Aguilar, M.J., Vinas, I., 2002. Evaluation of food additives and low-toxicity compounds as alternative chemicals for the control of Penicillium digitatum and Penicillium italicum on citrus fruit. Pest Manage. Sci., 58: 459-466.

Punja, Z. K., Gaye, M. M. 1993. Influence of postharvest handling practices and dip treatments on development of black root rot on fresh market carrots. Plant Disease, 77:989-995.

Schwartz, H.F., Mohan, S.K., 2008. Compendium of onion and garlic diseases and pests. 2nd eds. St Paul, MN, USA, APS Press, $136 \mathrm{p}$.

Sintayehu, A., Sakhuja, P.K., Fininsa, C., Seid Ahmed., 2011, Management of fusarium basal rot through fungicidal bulb treatment (Fusarium oxysporum $\mathrm{f}$. sp. cepae) on shallot. Crop Protection,30: 560-565.

Southwood, M.J., 2010. Evolution and detection of Fusarium oxysporum f. sp. cepae in onion in South
Africa. Stellenbosch University, PhD dissertation, Stellenbosch, South Africa, 170p.

Stadnik, M. J., Dhingra, O. D. 1996. Response of onion genotypes to Fusarium oxysporum f. sp. cepae during the growth phase and in storage. Fitopatologia Brasileira, 21: 431-435.

Thompson, D. P., 1989. Fungitoxic activity of essential oil componentson food storage fungi. Mycologia, 81:151-153.

Tian S. P., Fan Q., Xu Y., Wang Y., 2001. Effects of Trichosporon sp. in combination with calcium and fungicide on biocontrol of postharvest diseases in apple fruits. Acta Botanica Sinica, 43: 501 - 505.

Tripathi, P., Dubey, N. K., Banerji, R., Chansouria, J. P. N., 2004. Evaluation ofsome essential oils as botanical fungi toxicants in management ofpost-harvest rotting of citrus fruits. World J. Microbiol Biotechnol., 20:317-321.

TÜİK, 2016. https://biruni.tuik.gov.tr/bitkiselapp/bitkisel .zul (Erişim Tarihi: 20.09.2018).

Türkkan, M. Karaca, G. 2006. Amasya ili soğan ekiliş alanlarında bulunan fungal kök çürüklüğü hastalık etmenlerinin belirlenmesi. Tarım Bilimleri DergisiJournal of Agricultural Sciences, 12 (4): 357-363.

Türkkan, M. 2015. Evaluation of İnhibitory Effect of Organic and İnorganic Salts Againts Ilyonectria liriodendri, The Causal Agent of Root Rot Disease of Kiwifruit. J Phytopathol., 163(7-8):567-577.

Türkkan, M., Özcan, M., Erper, İ. 2017. Antifungal effect of carbonate and bicarbonate salts against Botrytis cinerea, the casual agent of grey mould of kiwifruit. Akademik Ziraat Dergisi, 6(2):103-110.

Youssef, K., Roberto, S. R. 2014. Applications of salt solutions before and after harvest affect the quality and incidence of postharvest gray mold of 'Italia' table grapes. Postharvest Biol Technol., 87: 95-102. 